Le général Joseph Servan de Gerbey (Romans, 1741Paris, 1808). Pour une armée au service de l'homme

\title{
Bernard Gainot
}

\section{(2) OpenEdition \\ 9 Journals}

Édition électronique

URL : https://journals.openedition.org/ahrf/1855

DOI : $10.4000 /$ ahrf. 1855

ISSN : 1952-403X

\section{Éditeur :}

Armand Colin, Société des études robespierristes

\section{Édition imprimée}

Date de publication : 1 décembre 2004

Pagination : 159-160

ISSN : 0003-4436

\section{Référence électronique}

Bernard Gainot, « Le général Joseph Servan de Gerbey (Romans, 1741-Paris, 1808). Pour une armée au service de l'homme ", Annales historiques de la Révolution française [En ligne], 338 | octobredécembre 2004, mis en ligne le 22 mars 2006, consulté le 24 avril 2022. URL : http:// journals.openedition.org/ahrf/1855; DOI : https://doi.org/10.4000/ahrf.1855

Ce document a été généré automatiquement le 24 avril 2022.

Tous droits réservés 


\title{
Le général Joseph Servan de Gerbey (Romans, 1741-Paris, 1808). Pour une armée au service de l'homme
}

\author{
Bernard Gainot
}

\section{RÉFÉRENCE}

Jacques-François Lanier, Le général Joseph Servan de Gerbey (Romans, 1741-Paris, 1808). Pour une armée au service de l'homme, Préface de Michel Vovelle, Valence, SRIG, 2001, 212 p., ISBN 2-9504360-7-2, 18, $30 €$.

1 Ce livre n'est pas une biographie du général Servan, mais une présentation, soit de quelques-uns de ses textes les plus fameux, soit de documents se rapportant à quelques-unes des principales étapes de sa carrière.

2 Dans sa présentation, Michel Vovelle nous rappelle que l'auteur est un érudit local qui s'intéresse depuis longtemps à la famille Servan, et qu'il a déjà consacré des études à des membres connus de celle-ci, l'avocat au Parlement de Grenoble, et l'abbé. Il rappelle les temps forts de la carrière de Joseph Servan, précisant toutefois que son apport théorique sur le «soldat-citoyen » est beaucoup plus important que son action militaire sous la Révolution.

Une bonne partie de l'ouvrage est effectivement consacrée à cet ouvrage publié en 1780. L'auteur nous en présente en quelque sorte les "bonnes feuilles ", de même que sa contribution à l'Encyclopédie méthodique (l'article "Guerre »). Servan synthétise le point de vue des réformateurs militaires de la monarchie finissante. Il exprime surtout le point de vue de son groupe social, la petite noblesse à vocation militaire, qui s'estime brimée par le monopole des places réservées aux courtisans. Ce point de vue n'est donc pas aussi radical que celui d'autres réformateurs qui préconisent une refonte totale de l'instrument militaire pour le mettre au service de la Nation (Guibert). Toutefois, par 
son insistance sur le mérite et le service public, il l'exprime dans un vocabulaire qui annonce les temps nouveaux.

4 À l'image de bien d'autres membres de cette petite noblesse militaire, Dubois-Crancé ou Lacuée de Cessac, Servan est favorable à la Révolution. Un texte de cette période illustre cet engagement révolutionnaire; le projet présenté au Comité militaire de la Constituante en 1789 , pour un service militaire obligatoire et universel. Enfin, un autre versant de l'œuvre de Servan est présenté avec son Histoire des guerres d'Italie depuis les Gaulois jusqu'à la Paix d'Amiens.

5 Comment le théoricien militaire s'est-il trouvé mêlé aux luttes politiques, et plus exactement comment a-t-il été amené à partager l'engagement politique des brissotins, jusqu'à occuper par deux fois le ministère de la Guerre en 1792 ? Nous restons sur notre faim, mais rappelons que ce livre n'est pas une biographie. Il présente le passage de Servan aux affaires, à travers un kaléidoscope de jugements empruntés aux historiens de la Révolution, depuis le XIXe siècle jusqu'à aujourd'hui (notamment pour l'affaire du camp des Fédérés de l'été 1792).

6 L'auteur insiste également beaucoup sur l'admiration que Servan portait à Bonaparte, aussi bien par son ralliement au régime consulaire que dans les pages qui relatent la campagne d'Italie. Pourtant, cette admiration n'était pas sans limites, et l'on sait qu'à la fin de sa vie, le général en était venu à réunir autour de lui un petit cénacle oppositionnel, que Malet cherchera à instrumentaliser dans sa première tentative conspirative de 1808 . Servan est toujours resté très proche des milieux républicains de La Décade philosophique, avec lesquels il était en contacts étroits à l'époque du Directoire. Sur ces aspects tout à fait fondamentaux, nous restons aussi sur notre faim. Pourtant, des pistes sont ouvertes dans sa correspondance, dont de nombreux extraits sont proposés de 1792 à 1804 ; avec Brissot, Madame Roland, ou Choderlos de Laclos, certes, mais aussi avec Marc-Antoine Jullien, Saint-Cyr Nugues, ou Hélène-Maria Williams, qui ne peuvent être abusivement qualifiés d'» inconnus de l'Histoire ». Il y a là des pistes tout à fait précieuses pour aller plus loin dans les relations publiques, ou discrètes, du général, afin de mieux appréhender ses opinions politiques.

7 Ce petit volume est donc précieux en ce qu'il met à notre portée un ensemble de textes de nature diverse, qui nous permettent de mieux situer un personnage qui ne fut pas seulement théoricien de la réforme militaire, mais aussi acteur engagé dans les réseaux d'influence culturelle et politique de son temps, avec une remarquable continuité, au moins de 1792 à 1808. Des matériaux indispensables pour une biographie qui reste à faire. 